\title{
Dual-Pulse Mode Control of A High-Speed Doubly Salient Electromagnetic Machine for Loss Reduction and Speed Range Extension
}

\author{
Li Yu, Member, IEEE, Zhuoran Zhang, Senior Member, IEEE, Zhangming Bian, \\ David Gerada and Chris Gerada
}

\begin{abstract}
In this paper, a dual-pulse mode control of a high-speed doubly salient electromagnetic machine (DSEM) for efficiency improvement over a wide speed range is investigated and implemented. The dual-pulse mode control method and operation principle are introduced. The influence of excitation angles and field current on the operation performance is analyzed by finite element method (FEM) based on the back-electromotive force (EMF) and inductance characteristics. The loss distribution for various speed and load torque requirement is attained, and the control parameters are optimized. The excitation angle can reduce the back-EMF at high speed through transformer-EMF and flux-weakening armature reaction. A prototype of 12/8-pole DSEM drive system is developed and dual-pulse mode control in high-speed operation under low DC-link voltage is implemented. Both the simulated and measured results show that the torque capacity of the DSEM is improved and the loss is reduced over a wide speed range.
\end{abstract}

Index Terms-Doubly salient machine, excitation angle, extended speed range, high-speed, loss reduction.

\section{INTRODUCTION}

The doubly salient electromagnetic machine (DSEM) has the inherent advantages of reliable and robust construction, and absence of the permanent magnet (PM), and it can operate in high-speed and harsh environment. The DSEM is attractive for a variety of applications that require the high reliability, such as the aircraft and vehicle applications [1], [2].

While the simple rotor structure of the DSEM is similar to the switched reluctance machine (SRM) [3], the difference is that the field winding on the stator provides the field magnetomotive force (MMF) and pre-excitation for each phase of the DSEM. Therefore, in the motoring operation, the power factor of the DSEM is improved and the volt-ampere capacity of the converter is reduced compared to the SRM [4]. The

Manuscript received December 17, 2018; revised May 14 and June 22, 2019; accepted July 16, 2019. This work was supported in part by the National Natural Science Foundation for Excellent Young Scholar of China under Award 51622704 and in part by the State Key Program of National Nature Science Foundation of China (Grant No. 51737006). (Corresponding author: Zhuoran Zhang.)

$\mathrm{Li} \mathrm{Yu}$, Zhuoran Zhang and Zhangming Bian are with the Center for More-Electric-Aircraft Power System, Nanjing University of Aeronautics and Astronautics, Nanjing, China (e-mail: yulipc@126.com, apsc-zzr@nuaa.edu.cn, bzm@nuaa.edu.cn).

David Gerada, Chris Gerada are with the Department of Electrical Engineering, University of Nottingham, Nottingham, UK. (e-mail: david.gerada@nottingham.ac.uk, chris.gerada@nottingham.ac.uk).
DSEM can operate with bidirectional phase current and the conventional full-bridge converter can be employed. The airgap magnetic field can be regulated by varying the field current.

High efficiency is a significant target for the motor drives. For the DSEM, the field current regulates the backelectromotive force (EMF) flexibly, but it also brings extra field copper loss. However, compared to the SRM the phase current of the DSEM does not take on the excitation function and thus the armature copper loss is reduced. The iron loss is also related with the field and armature current. Therefore, the reduction of the total copper and iron loss can be achieved by proper regulation of the field current and armature current, while meeting the torque requirement. [5] proposes an asymmetric current control method to improve output torque in current chopping mode at low and medium speed. It focuses on the influence of excitation angles. The copper loss with variation of the armature and field current is not analyzed. [6] analyzes the advanced angles deduced under various speed and armature current, however, under the condition of a certain constant field current.

The wide-speed-range operation is also required for many drive applications such as the electric vehicle drive system [7], and the aircraft starter/generator system [8]. For the auxiliary power unit (APU) starter/generator system, the battery-powered DC-link voltage for the starting operation is low [9]. The DSEM can regulate the field current to reduce the back-EMF [5], [10]. However, very few literatures address the comprehensive regulation method of the field current and armature current for extending the speed range and improving the efficiency of DSEM.

The current chopping control conventionally adopted for low-speed operated SRM is categorized into the instantaneous torque control and average torque control [11], [12]. For highspeed operation, the back-EMF is increased and the DC-link voltage is insufficient for chopping. Then the single-pulse control is adopted only by varying the excitation angles [13], [14]. In single-pulse mode, the average torque is controlled rather than the instantaneous torque. The switching frequency and loss of the associated converter are decreased [15]. The iron loss is decreased due to reduction of the local minor hysteresis loop [16]. Moreover, the AC copper loss is also decreased [17].

The non-chopping control can also be used for the DSEM. Due to the use of the full-bridge converter, the armature current of the DSEM is bidirectional, so the operation mode under the non-chopping control is called the dual-pulse mode. As 
mentioned before, the back-EMF of the DSEM can be changed by regulating the field current so as to extend the speed range. The extended speed range can also be achieved by varying the excitation angles of the DSEM. The excitation angles of the DSEM include not only the turn-on angle and the turn-off angle, but also the reversal angle used to change the phase current polarity within one electric cycle. Different from the SRM driven by the asymmetric half bridges, each phase of the DSEM is not controlled independently. Therefore, the variation of the armature current is more complicated in the dual-pulse mode control.

In this paper, the dual-pulse mode control of the high-speed DSEM is investigated under low DC-link voltage. A coordinated control method of the field current and excitation angles is proposed to achieve the optimized performance over a wide speed range. The improvements of the proposed control method are verified through the simulated and experimental results.

\section{OpERATION PRINCIPLE}

\section{A. Torque Generation Principle}

The DSEM has a salient-pole stator with the armature and field windings, and a salient-pole rotor without magnet or coils. The well-established full-bridge converter used for the conventional synchronous and induction machines can be used for the DSEM, and an asymmetric half-bridge converter or simpler buck converter is used to regulate the unipolar field current, as shown in Fig. 1. The torque produced by a single phase is

$$
T_{e}\left(I_{p h}, I_{f}, \theta\right)=\left.\frac{\partial W_{c o}\left(I_{p h}, I_{f}, \theta\right)}{\partial \theta}\right|_{\substack{I_{p h}=\text { const. } \\ I_{f}=\text { const. }}}
$$

where $W_{\mathrm{co}}$ is the co-energy, $\theta$ is the rotor angle, $I_{\mathrm{ph}}$ and $I_{\mathrm{f}}$ are the phase current and field current respectively.

Neglecting the magnetic saturation, (1) can be rewritten as [4]

$$
T_{e}\left(I_{p h}, \theta\right)=\frac{1}{2} I_{p h}^{2} \frac{d L_{p h}(\theta)}{d \theta}+I_{p h} I_{f} \frac{d M_{p h-f}(\theta)}{d \theta}
$$

where $L_{\mathrm{ph}}(\theta)$ and $M_{\mathrm{ph}-\mathrm{f}}(\theta)$ are phase self-inductance and mutual-inductance between the phase winding and field winding respectively. $M_{\mathrm{ph}-\mathrm{f}}(\theta)$ is larger than $L_{\mathrm{ph}}(\theta)$ due to the more turns of the field winding. The incremental inductance $d M_{\mathrm{ph}-\mathrm{f}}(\theta) / d \theta$ is also larger than $d L_{\mathrm{ph}}(\theta) / d \theta$.

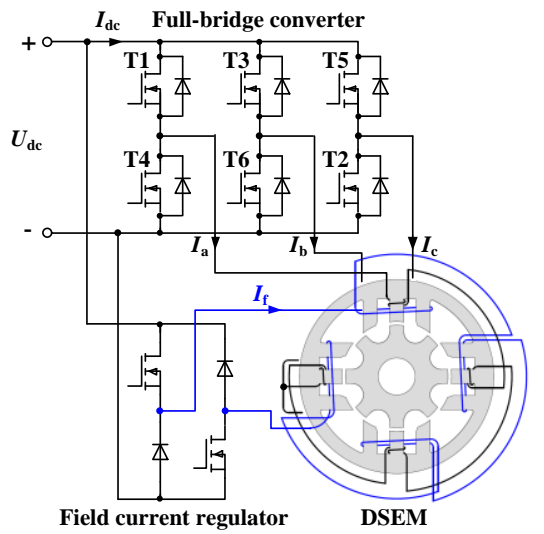

Fig. 1. Topologies of full-bridge converter and field current regulator of DSEM.

\section{B. Current chopping and Dual-Pulse Mode}

The amplitude of the line-to-line back-EMF of the DSEM is increased with the increase of the speed and field current as shown in Fig. 2. At low speed, the line-to-line back-EMF is lower than the DC-link voltage, when the rated field current is applied. Thus the phase current is regulated by chopping to produce the required torque.

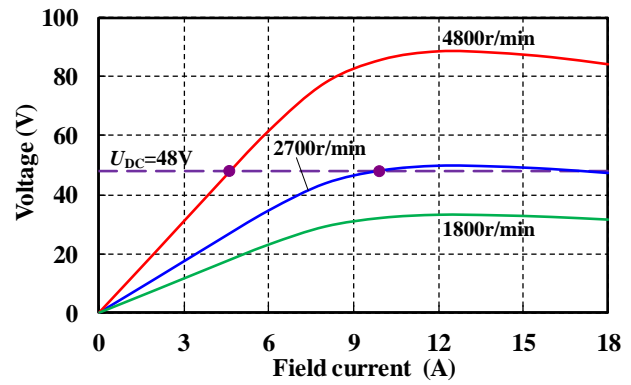

Fig. 2. Amplitude of line-to-line back-EMF versus field current at different speed.

At high speed, the line-to-line back-EMF may be higher than the DC-link voltage. The available DC-link voltage is insufficient for chopping. Although, by reducing the field current, the amplitude of line-to-line back-EMF can be lower than the DC-link voltage as shown in Fig. 3, the stored field energy is too small to generate the sufficient torque. When the speed is $3000 \mathrm{r} / \mathrm{min}$, the corresponding field current is set to $8 \mathrm{~A}$, which ensures the line-to-line back-EMF equal to the DC-link voltage. However, the field current is decreased quickly with the increase of the speed. Therefore, at high speed, the dualpulse mode control is used for the DSEM with high back-EMF.

The presented study is aimed at investigation of the performance optimization of the high-speed operated DSEM with dual-pulse mode control.

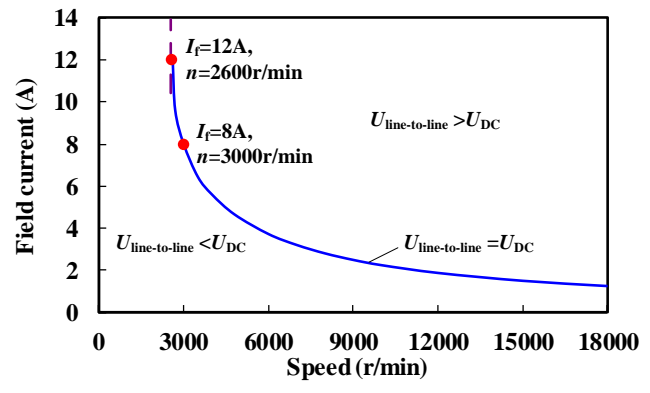

Fig. 3. Field current versus speed when amplitude of line-to-line backEMF of DSEM is equal to DC-link voltage.

\section{Control Parameters in Dual-Pulse Mode}

\section{1) Excitation Angles:}

Fig. 4 shows the typical waveforms of the idealized inductance and the phase current in dual-pulse mode.

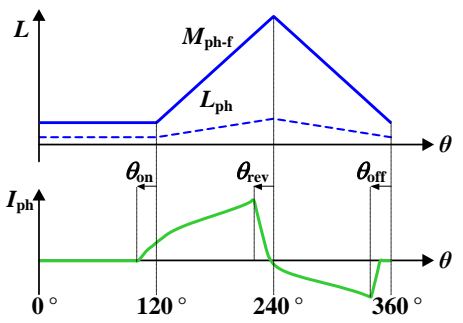

Fig. 4. Illustration of excitation angles for dual-pulse mode control. 


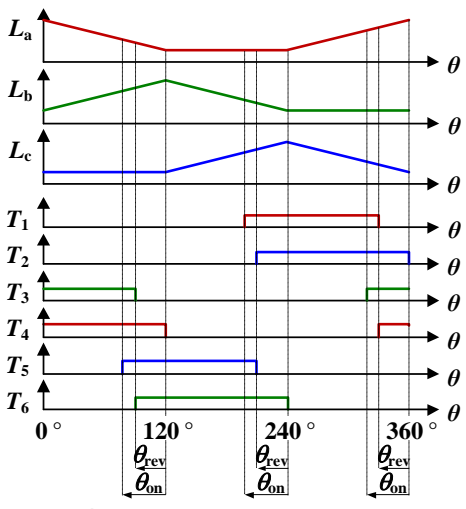

Fig. 5. Conduction modes.

For the dual-pulse mode control, the control parameters are excitation angles including the turn-on angle $\theta_{\text {on }}$, reversal angle $\theta_{\text {rev }}$ and turn-off angle $\theta_{\text {off }}$, as well as the field current $I_{\mathrm{f}}$. When $\theta_{\text {off }}$ is positive, the phase current is turned off in advance and thus this phase cannot generate torque adequately. When $\theta_{\text {off }}$ is negative, the armature copper loss is increased. Therefore, $\theta_{\text {off }}$ is set to zero. Fig. 5 shows the conduction modes with $\theta_{\text {off }}$ set to zero. Due to the use of the full-bridge converter, the excitation angles are restricted as

$$
\left\{\begin{array}{l}
0^{\circ} \leq \theta_{\text {on }}<120^{\circ} \\
0^{\circ} \leq \theta_{\text {rev }}<120^{\circ} \\
\theta_{\text {rev }} \leq \theta_{\text {on }}
\end{array} .\right.
$$

By contrast, it is worth noting that the phase current of the high-speed SRM with single-pulse mode control is unidirectional and pulse-shape, which leading to the larger peak value of the phase current and the larger requirement of the power converter capacity for the SRM.

\section{2) Field Current:}

The field current can change the back-EMF and the inductance, both of which are important parameters for motor control. The A-phase flux linkage waveform is shown in Fig. 6 (a). When the rotor pole is aligned with the A-phase stator pole, the A-phase flux linkage reaches peak value. The flux linkage is decreased with the rotor pole sliding off stator pole. When the rotor slot is aligned with the A-phase stator pole, the A-phase flux linkage is minimum. When the next adjacent rotor pole is sliding into the A-phase stator pole, the phase flux linkage is increased. Thus, the phase flux linkage is variable in the different rotor positions.

The phase flux linkage is related with the field current as shown in Fig. 6 (b). When the field current is small, the iron core is not saturated, and thus, the phase flux linkage is proportional to field current. When the field current is relatively large, the iron core is saturated and the phase flux linkage is increased slowly with the increase of the field current.

Therefore, the phase flux linkage is a function of the rotor position and the field current.

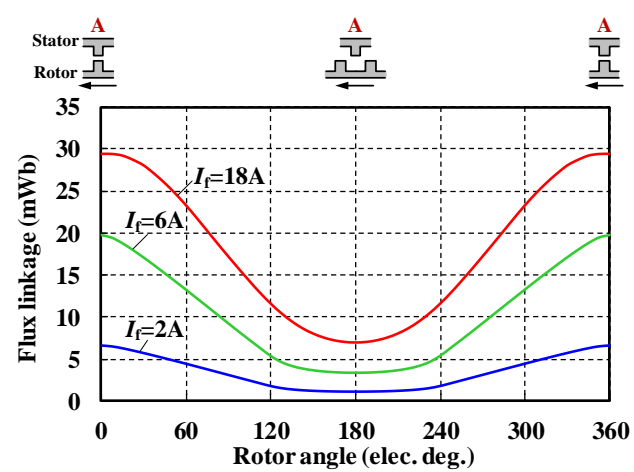

(a)

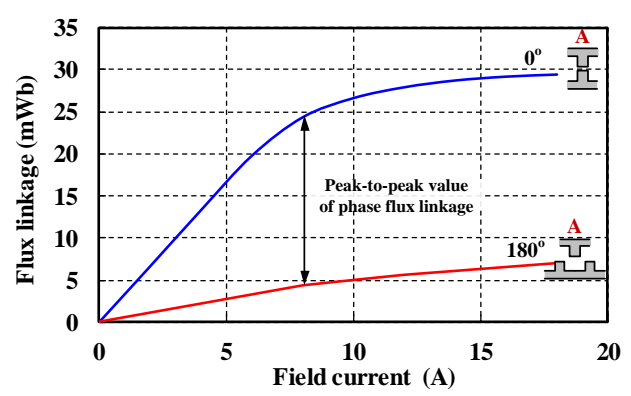

(b)

Fig. 6. A-phase flux linkage. (a) Flux linkage waveforms. (b) Flux linkage versus field current.

The back-EMF $E$ is calculated as

$$
E=\frac{d \psi_{f}\left(\theta, I_{f}\right)}{d \theta} \omega_{r}
$$

where $\psi_{\mathrm{f}}$ is flux linkage, $\omega_{\mathrm{r}}$ is electrical angular velocity. The A-phase back-EMF waveform is shown in Fig. 7. The backEMF is proportional to the rotation speed and the rate of the flux linkage change, respectively. Thus the amplitude of lineto-line back-EMF is a function of rotation speed and field current as shown in Fig. 2. When the field current is large, the peak-to-peak value of the flux linkage is almost held constant and even slightly decreased with the increase of the field current, because the saturation is more severe when the rotor pole is aligned with the stator pole. Therefore, the amplitude of lineto-line back-EMF is decreased slightly with the increase of the field current when the field current is large as shown in Fig. 2.

Fig. 8 shows the phase self-inductance in different rotor positions. When the rotor pole is exactly aligned with the stator pole, the corresponding phase self-inductance is at its maximum. As the field current grows to $6 \mathrm{~A}$, the core saturation appears and the inductance is decreased.

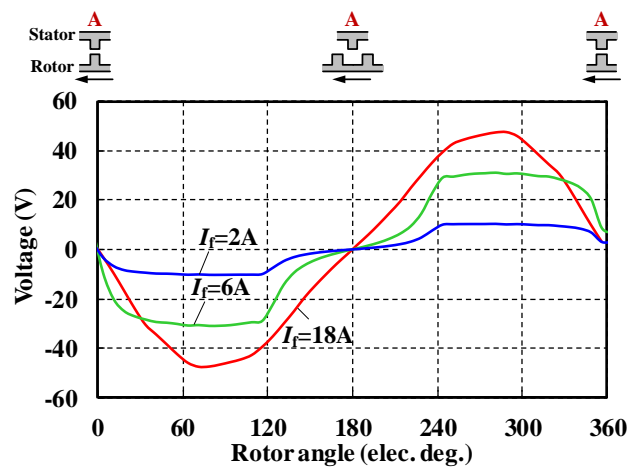

Fig. 7. A-phase back-EMF in different rotor positions. 


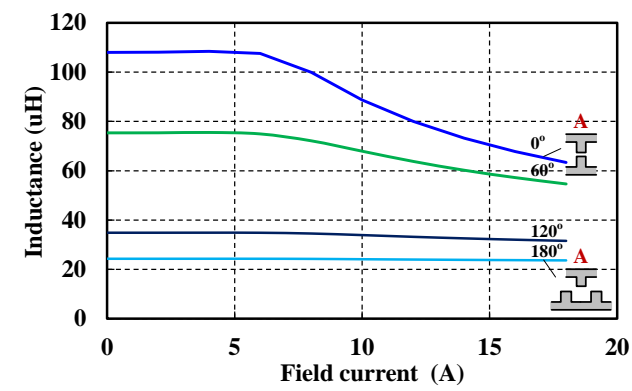

Fig. 8. A-phase self-inductance versus field current in different rotor positions.

\section{Performance Analysis With Dual-Pulse MODE CONTROL}

Table I shows the key parameters of the DSEM and drive system. The operation performance of the DSEM with dualpulse mode control is analyzed by field-circuit coupling method.

The resistance of phase winding is $7 \mathrm{~m} \Omega$, the aligned phase inductance is $110 \mu \mathrm{H}$, and the unaligned phase inductance is $25 \mu \mathrm{H}$. Assuming that two phases conduct at the same time, considering the phase inductance is variable, the minimum time constant is around $3.6 \mathrm{~ms}$ and the maximum time constant is around $9.6 \mathrm{~ms}$.

TABLE I

DSEM AND DRIVE PARAMETERS

\begin{tabular}{lc}
\hline \hline \multicolumn{1}{c}{ Parameters } & Value \\
\hline Number of stator poles & 12 \\
Number of rotor poles & 8 \\
Stator outer diameter & $158 \mathrm{~mm}$ \\
Stator inner diameter & $90 \mathrm{~mm}$ \\
Airgap length & $0.7 \mathrm{~mm}$ \\
Core length & $120 \mathrm{~mm}$ \\
Turns per phase coil & 3 \\
Turns per DC field coil & 100 \\
Aligned phase inductance & $110 \mu \mathrm{H}$ \\
Unaligned phase inductance & $25 \mu \mathrm{H}$ \\
Resistance of phase winding & $7 \mathrm{~m} \Omega$ \\
DC-link voltage & $48 \mathrm{~V}$ \\
\hline \hline
\end{tabular}

\section{A. Influence of Excitation Angle}

When the field current is $4 \mathrm{~A}$ and the speed is $4800 \mathrm{r} / \mathrm{min}$, the amplitude of the line-to-line voltage is close to the DC-link voltage. Fig. 9 shows the phase self-inductance, phase current, phase flux linkage, phase terminal voltage and torque when the excitation angles is set to zero. The dashed waveforms represent conditions without armature current, defined as no-load waveforms. Because of the change of the phase current and phase inductance, the phase terminal voltage at load is different from the no-load voltage. Fig. 10 shows the corresponding converter operating modes.

In mode 1, the B-phase and C-phase currents are reduced with the turn-off state of the power switches $T 5, T 6$ and the turnon state of $T 1, T 2$. The back-EMF of A-phase is relatively high at the rotor angle of $240^{\circ}$. The A-phase current flows through the diode $D 1$ rather than $T 1$. The freewheeling currents of $\mathrm{B}$ and C-phase flow through $D 3$ and $D 2$ respectively, as shown in Fig. 10 (a).

In mode 2, the B-phase current is decreased to zero. The Aphase current through $D 1$ is decreased. In mode 1 and mode 2, the energy returns from the motor side to the power supply side, and the instantaneous torque is negative, as shown in Fig. 10 (b).

In mode 3, the A and C-phase currents reverse. The rate of the phase current rise is small due to the high back-EMF of Aphase and C-phase in this stage, as shown in Fig. 10 (c).

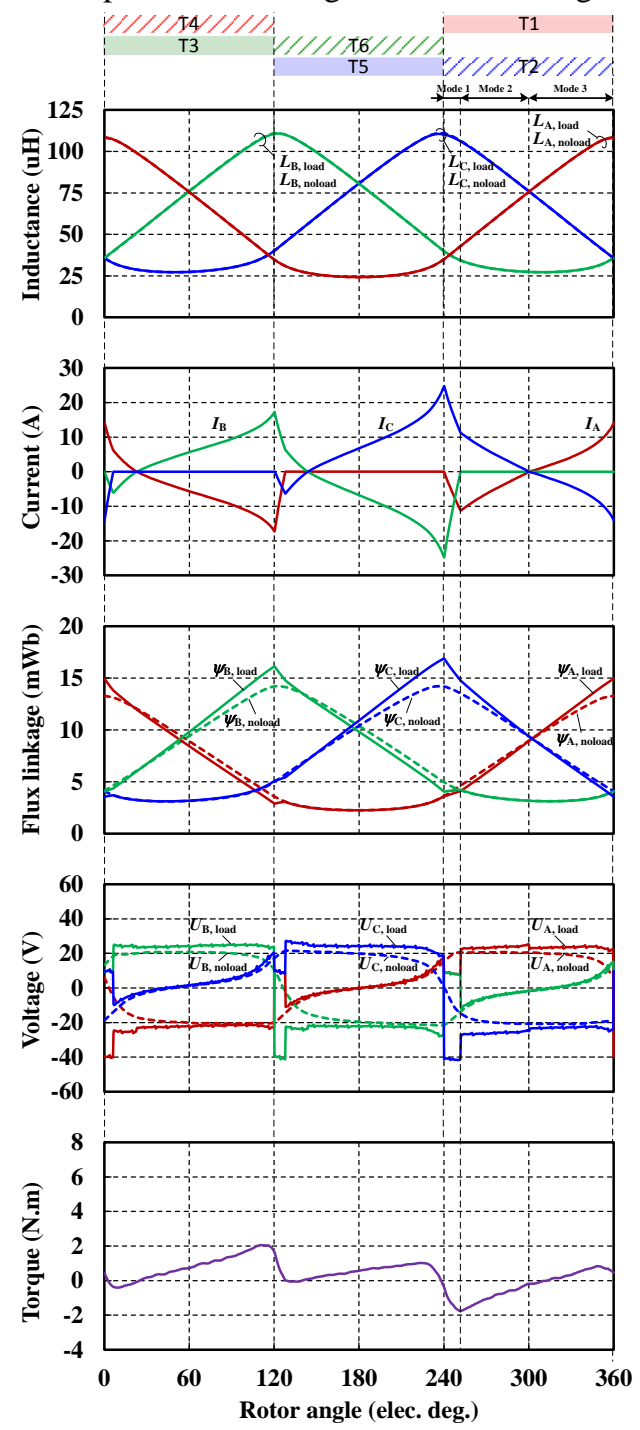

Fig. 9. Phase self-inductance, phase current, phase flux linkage, phase terminal voltage and torque $\left(\theta_{\mathrm{on}}=0^{\circ}, \theta_{\mathrm{rev}}=0^{\circ}, \mathrm{l}_{\mathrm{l}}=4 \mathrm{~A}, n=4800 \mathrm{r} / \mathrm{min}\right)$.

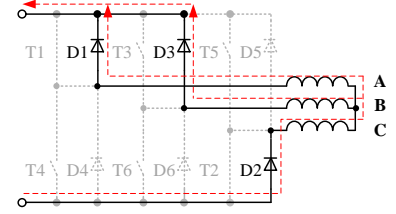

(a)

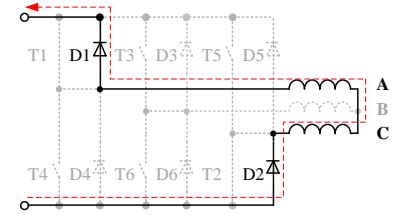

(b)

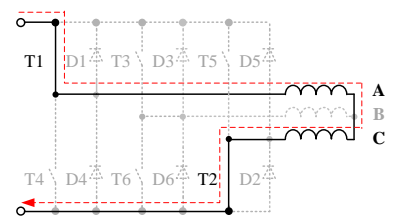

(c)

Fig. 10. Operating modes of full-bridge converter $\left(\theta_{0 \mathrm{on}}=0^{\circ}, \theta_{\mathrm{rev}}=0^{\circ}, l_{\mathrm{f}}=4 \mathrm{~A}\right.$, $n=4800 \mathrm{r} / \mathrm{min}$ ). (a) Mode 1. (b) Mode 2. (c) Mode 3.

Fig. 11 indicates energy conversion cycles under different speeds in dual-pulse mode, and the excitation angles are set to zero. As the speed increases, the back-EMF is increased and the 
rate of the phase current change is decreased. The areas enclosed by the loops corresponding to the energy converted from electrical to mechanical form are significantly reduced with the increase of the speed. Moreover, the "concave triangle" is presented because the phase current is negative during increase of the phase flux linkage, as shown in the mode 1 and mode 2 of the A-phase current in Fig. 9. The "concave triangle" is caused by the high neutral point voltage and high back-EMF at high speed, and it reduces the output torque. Since the backEMF of A-phase is variable with the rotation speed, the A-phase current in mode 1 and mode 2 shown in Fig. 9 is variable with the speed. Therefore, the area of the "concave triangle" is also variable with the rotation speed.

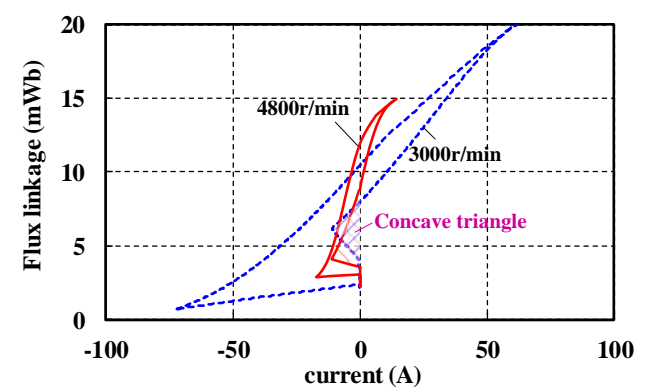

Fig. 11. Energy conversion cycles of A-phase for $\operatorname{DSEM}\left(\theta_{\mathrm{on}}=0^{\circ}, \theta_{\mathrm{rev}}=0^{\circ}\right.$, $\left.l_{\mathrm{f}}=4 \mathrm{~A}\right)$.

The no-load A-phase voltage and self-inductance are decreased before the rotor position of $240^{\circ}$ which facilitates increase of the rate of phase current change, likewise for the B and C-phase, thus enabling the current to rise to a reasonable level before the back-EMF dominates. The turn-on angle $\theta_{\text {on }}$ is set to $40^{\circ}$ in Fig. 12.

In mode 1 , when $T 1$ is turned on, the back-EMF of A-phase is low. The inductance is small. The neutral point voltage $U_{\mathrm{n}}$ is

$$
U_{n}=-U_{b}=\left(-L_{b} \frac{d I_{b}}{d t}\right)+\left(-I_{b} \frac{d L_{b}}{d \theta} \omega_{r}\right)+\left(-I_{f} \frac{d M_{b-f}}{d \theta} \omega_{r}\right) .
$$

The B-phase self-inductance is small in this stage. Meanwhile, the second term of right side of (5) is negative since the incremental inductance $d L_{b} / d \theta$ is negative. Thus the neutral point voltage is relatively small. For these reasons, the A-phase current is increased more rapidly.

In mode 2, when $T 5$ and $T 6$ are turned off, the freewheeling currents of B and C-phase flow through $D 3$ and $D 2$. The neutral point voltage is equal to C-phase voltage due to $D 2$ conducting,

$$
U_{n}=-U_{c}=\left(-L_{c} \frac{d I_{c}}{d t}\right)+\left(-I_{c} \frac{d L_{c}}{d \theta} \omega_{r}\right)+\left(-I_{f} \frac{d M_{c-f}}{d \theta} \omega_{r}\right) .
$$

The C-phase self-inductance is relatively large. The second term of the right side is positive. Thus the neutral point voltage is increased significantly. Meanwhile, the back-EMF of Aphase is also increased in this stage. Therefore, the A-phase current is reduced, as well as the torque. In mode 3, the B-phase current is decreased to zero. The $\mathrm{C}$-phase current through $T 2$ is increased. In mode 4, the currents of $\mathrm{A}$ and $\mathrm{C}$-phase are increased slowly due to the high back-EMF.

It can be seen from Fig. 12 that the phase current is relatively small, and thus, the torque is small and even slightly below zero at around $280^{\circ}$. The phase current can be further increased when the turn-on angle advanced to $80^{\circ}$ as shown in Fig. 13. However, it is worth noting that when $T 1$ is just turned on, the A-phase current is still negative and flows through $D 1$. Therefore, the further advanced turn-on angle has no effect on the phase current and torque, as shown in Fig. 14.

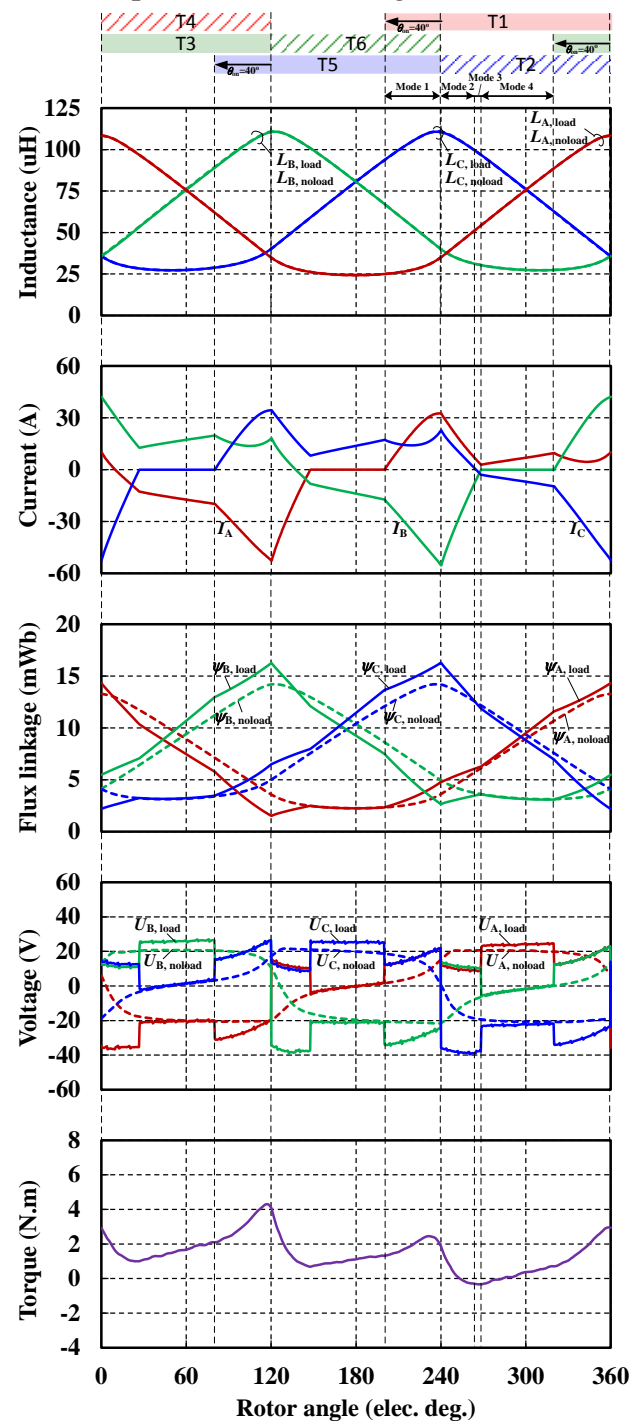

Fig. 12. Phase self-inductance, phase current, phase flux linkage, phase terminal voltage and torque $\left(\theta_{\mathrm{on}}=40^{\circ}, \theta_{\mathrm{rev}}=0^{\circ}, l_{\mathrm{f}}=4 \mathrm{~A}, n=4800 \mathrm{r} / \mathrm{min}\right)$.

On the basis of the advance of turn-on angle, the reversal angle is also advanced to further increase the amplitude of the phase current. Fig. 15 shows the phase current waveforms with $\theta_{\text {on }}$ of $80^{\circ}$ and $\theta_{\text {rev }}$ of $80^{\circ}$. The positive A-phase current is increased more significantly. The average torque is increased. The torque ripple is large. At high speed, the torque ripple has high frequency and is filtered by the mechanical inertia of the drive train.

\section{B. Losses Reduction and Speed Range Extension with Optimized Control Parameters}

Fig. 16 (a) shows the torque versus different $\theta_{\text {on }}$ and $\theta_{\text {rev }}$ when the field current is 4A. Fig. 16 (b) shows the copper and iron loss. The iron loss is separated into the hysteresis loss and eddy current loss, and the minor hysteresis loops are taken into consideration [18]. The DC bias flux exists in the stator due to 
the DC field MMF. Thus the DC bias coefficient is used for the hysteresis loss calculation [19].
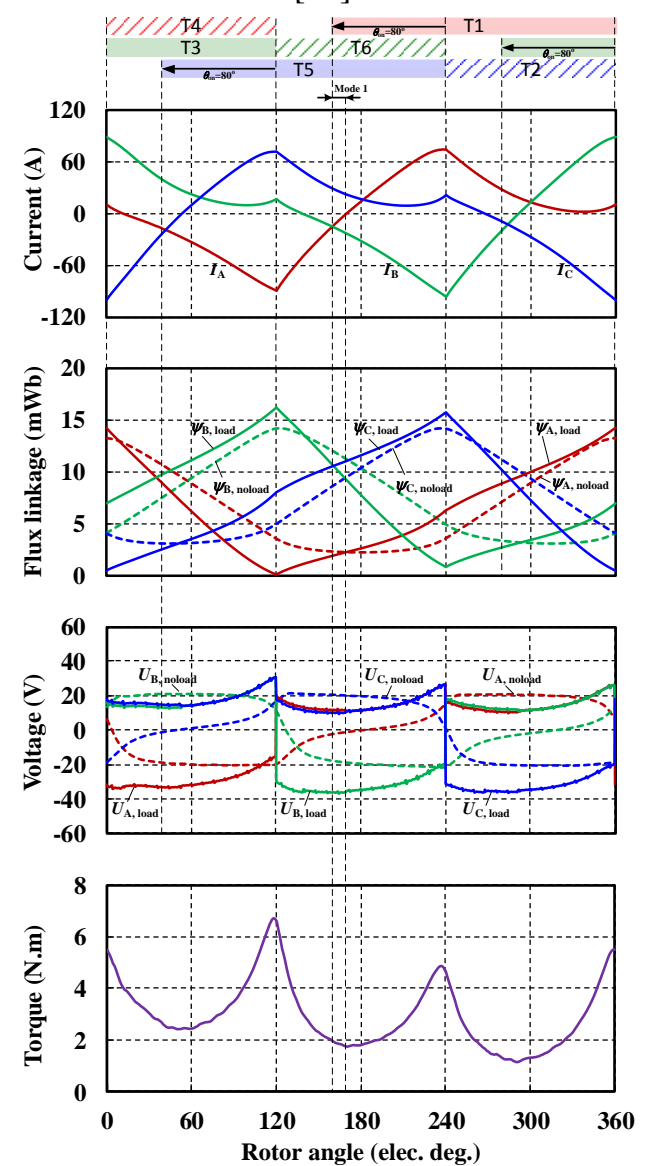

Fig. 13. Phase current, phase flux linkage, phase terminal voltage and torque $\left(\theta_{\mathrm{on}}=80^{\circ}, \theta_{\mathrm{rev}}=0^{\circ}, l_{\mathrm{f}}=4 \mathrm{~A}, n=4800 \mathrm{r} / \mathrm{min}\right)$.

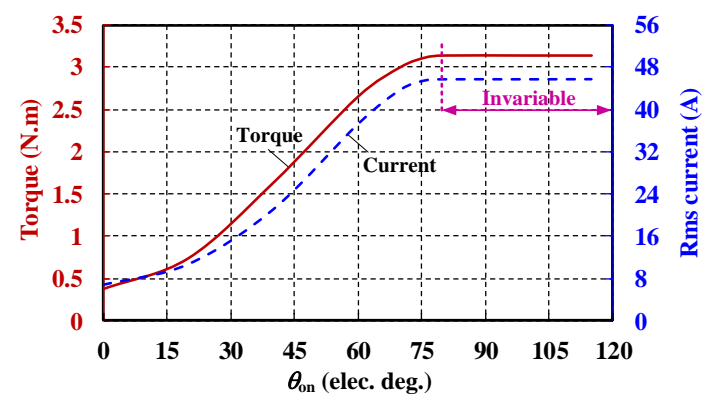

Fig. 14. Torque and rms phase current versus turn-on angle $\left(\theta_{\mathrm{rev}}=0^{\circ}\right.$, $\left.l_{\mathrm{f}}=4 \mathrm{~A}, n=4800 \mathrm{r} / \mathrm{min}\right)$.

In Fig. 16 (a), the magenta lines represent various output torque and the black dotted lines represent various rms phase current. Taking the copper and iron loss into consideration, the optimized turn-on angle and reversal angle are selected for the minimum loss while meeting the torque requirement, as marked by magenta points in Fig. 16 (a). It can be seen that for different desired torque requirements, the minimum loss is achieved when $\theta_{\text {on }}$ is almost equal to $\theta_{\text {rev }}$. Meanwhile, the minimum phase current exhibits with $\theta_{\mathrm{on}}$ equal to $\theta_{\mathrm{rev}}$, and thus the maximum torque-to-current ratio is achieved. Therefore, the collaborative optimization of the field current and excitation angle is carried on with the turn-on angle and reversal angle set to the same, which can also simplify the control.

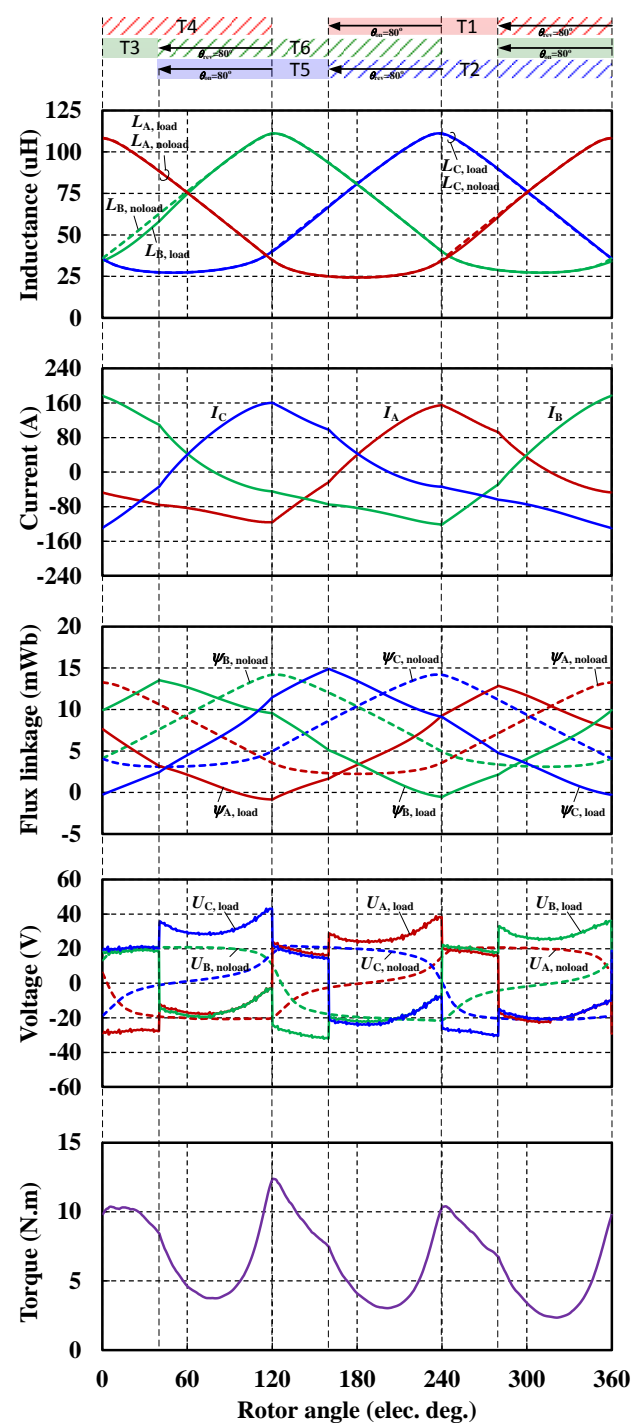

Fig. 15. Phase self-inductance, current, flux linkage, phase terminal voltage and torque $\left(\theta_{\mathrm{on}}=80^{\circ}, \theta_{\mathrm{rev}}=80^{\circ}, l_{\mathrm{f}}=4 \mathrm{~A}, n=4800 \mathrm{r} / \mathrm{min}\right)$.

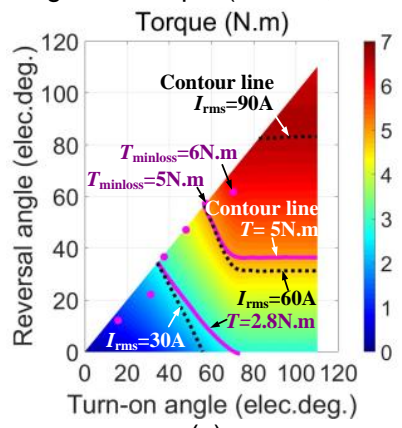

(a)

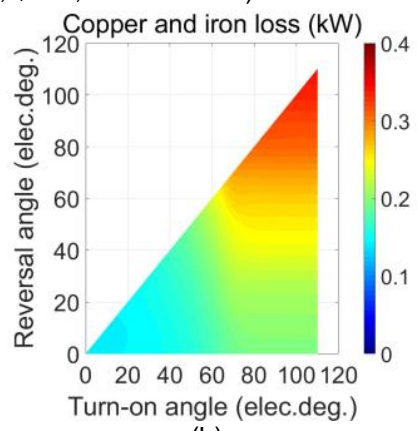

(b)
Fig. 16. Variation of (a) average torque and (b) loss, versus turn-on angle and reversal angle $\left(I_{f}=4 \mathrm{~A}, n=4800 \mathrm{r} / \mathrm{min}\right)$.

Fig. 17 shows the dual-pulse mode control system of DSEM. A look-up table derived from offline optimization generates turn-on angle and field current to minimize losses over a wide speed range and torque requirements. The field current is regulated together with turn-on angle according to the torque requirement for loss reduction. In the event of a converter failure, the field current is cut off to ensure safe operation at high speed. 


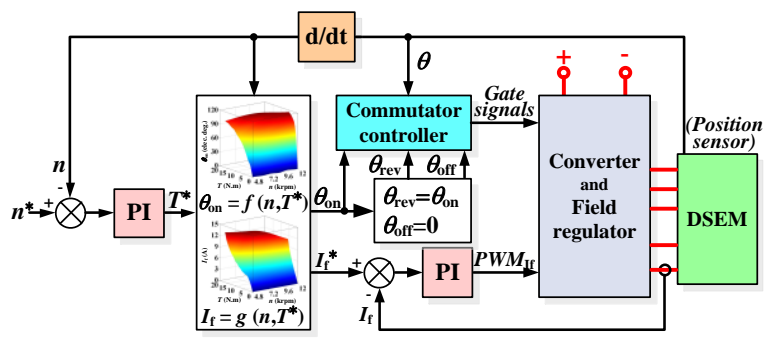

Fig. 17. Block diagram of dual-pulse mode control system of DSEM.

The torque, as well as loss and rms phase current versus field current and turn-on angle is shown in Fig. 18. The black dotted line represents the limit phase current of $100 \mathrm{~A}$, and thus the maximum torque is limited by the phase current. The magenta points represent the various torque of minimum loss. At the same speed, when the desired torque is changed, the field current and turn-on angle need to be changed synergistically for loss minimization.
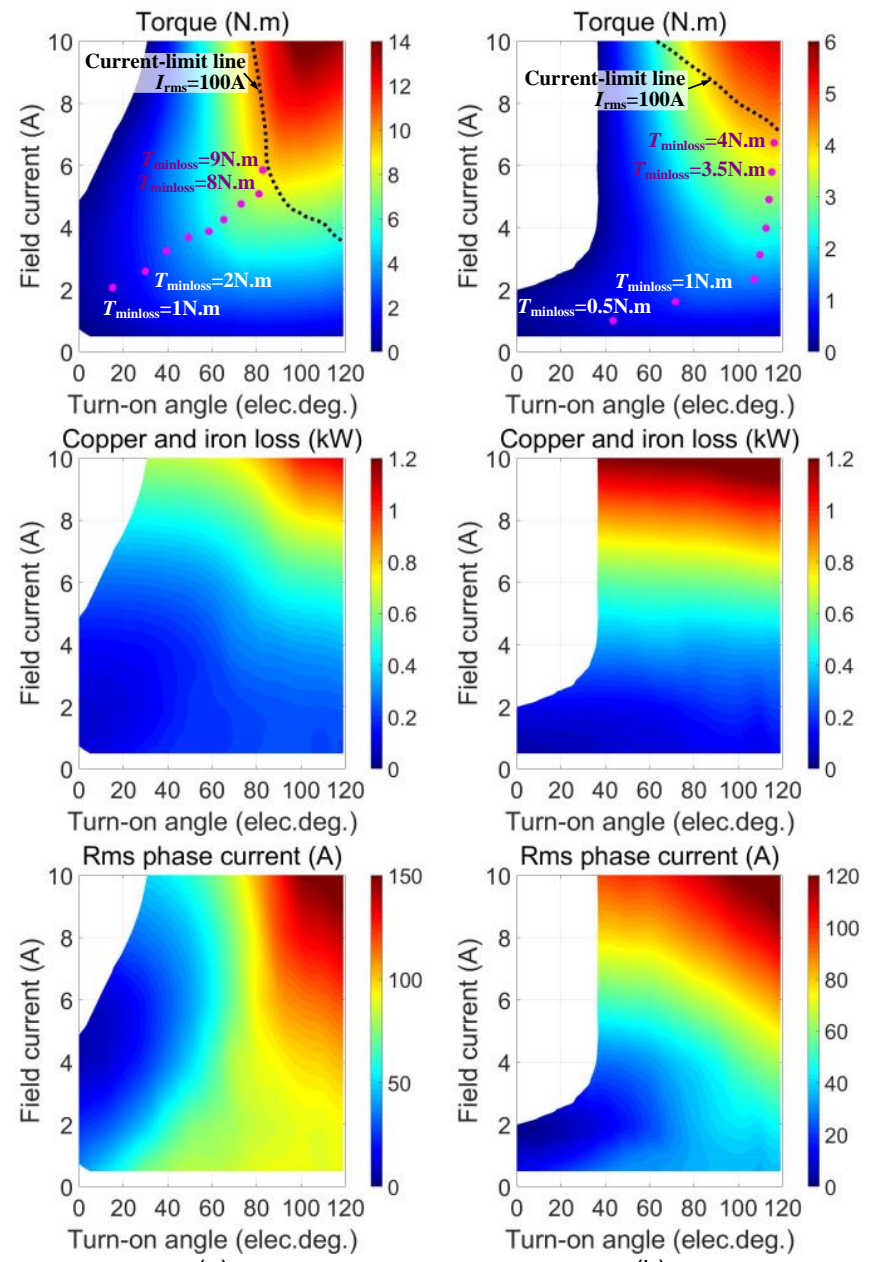

(a)

(b)

Fig. 18. Variation of average torque, loss and rms phase current versus turn-on angle and field current at (a) $n=4800 \mathrm{r} / \mathrm{min}$ and (b) $n=12000 \mathrm{r} / \mathrm{min}$.

The increase of the field current increases the back-EMF, thereby limiting the increase of phase current. As shown in Fig. 19 (a), when the turn-on angle is small, the phase current gradually decreases with the increase of the field current until it is reduced to zero. When the field current continues to grow to $4 \mathrm{~A}$, the line-to-line back-EMF exceeds DC-link voltage and the phase current is increased again. However, during the decrease of the A-phase inductance, the phase current is from negative to positive and flows through $D 4$ due to the high backEMF. The torque produced by A-phase is negative during the interval that the A-phase inductance is decreased and A-phase current is positive. Likewise, the torque produced by A-phase is also negative during the interval that the A-phase inductance is increased and A-phase current is negative. Therefore, though the phase current is increased, the torque produced is negative.

Fig. 19(b) shows the phase current waveforms with a relatively large turn-on angle. For large field current, when $T 1$ is turned on, the A-phase current is still positive and will flow through $T 1$ which is different from Fig. 19(a). The positive phase current then increases because the phase inductance and back-EMF are not large in this rotor position. The duration of the negative phase current is longer because the reversal angle is also large. It is worth noting that the transformer EMF induced by the decrease of phase current reduces the back-EMF when the rotor pole is sliding into the stator pole, and fluxweakening armature reaction reduces the back-EMF when the rotor pole is sliding off the stator pole. Thus the positive torque can be produced even for high field current when the turn-on angle is large.

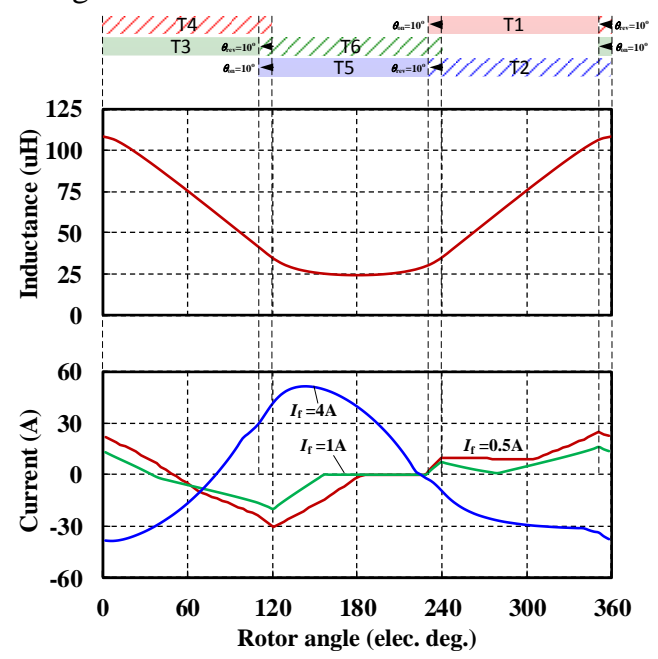

(a)

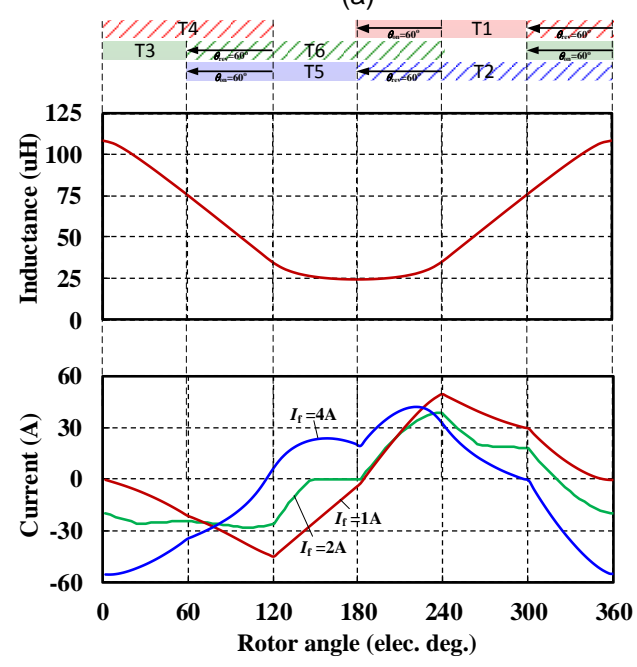

(b)

Fig. 19. A-phase self-inductance and A-phase current with different field current at $12000 \mathrm{r} / \mathrm{min}$. (a) $\theta_{\mathrm{on}}=10^{\circ}$. (b) $\theta_{\mathrm{on}}=60^{\circ}$. 


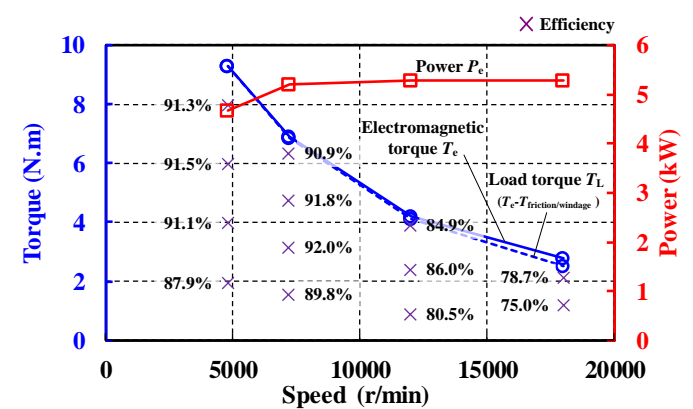

(a)

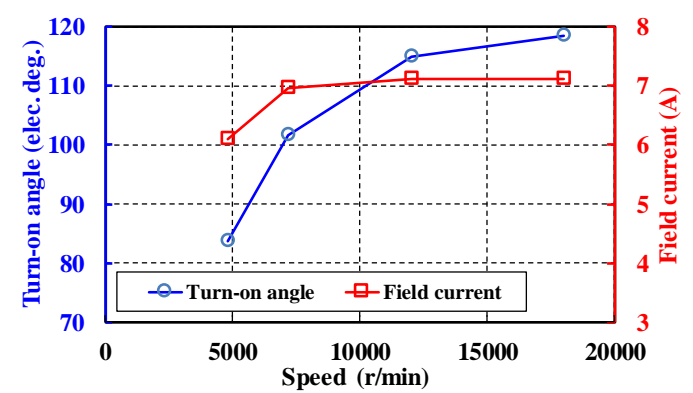

(b)

Fig. 20. (a) Extended torque-speed curve, and (b) regulation of turn-on angle and field current over extended speed range with reduced loss.

Fig. 20(a) shows the torque-speed curve, and the efficiency considering the copper loss, iron loss and mechanical loss. The constant power of $5.2 \mathrm{~kW}$ exhibits over a wide speed range from $4800 \mathrm{r} / \mathrm{min}$ to $18000 \mathrm{r} / \mathrm{min}$, by regulating the field current and turn-on angle according to Fig. 20(b), though the line-to-line back-EMF is higher than the DC-link voltage. The turn-on angle is regulated to increase with the increase of the speed. The proper turn-on angle can reduce the back-EMF through the induced transformer EMF and flux-weakening armature reaction, and boost the phase current. While reducing the field current reduces the magnitude of the back-EMF, it reduces the magnetic energy and weakens the torque capability.

\section{EXPERIMENTAL RESULTS}

A three-phase 12/8-pole DSEM prototype is designed and manufactured. Litz-wire phase winding is used to minimize the AC loss [20]. The key parameters are listed in Table I, and the prototype and test rig are shown in Fig. 21. Fig. 22 shows the hardware platform diagram. The DC-link voltage is $48 \mathrm{~V}$, and the three-phase full-bridge power converter using air-cooling is employed. Since the dual-pulse control mode is used at high speed, the switching frequency of the power converter is decreased. The supply frequency is $2.4 \mathrm{kHz}$ at $18000 \mathrm{r} / \mathrm{min}$.

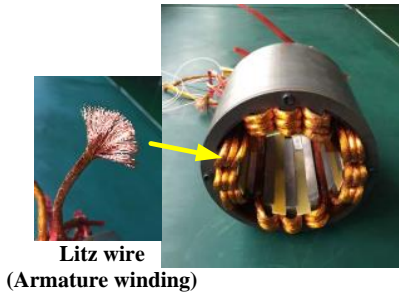

(a)

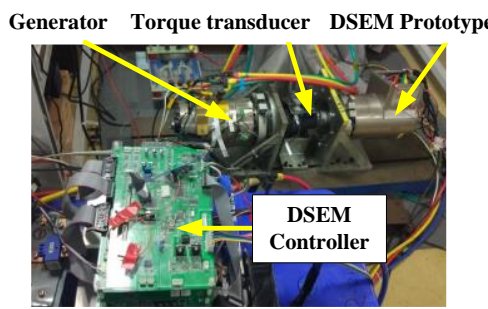

(b)
Fig. 21. (a) Stator wound with Litz-wire phase winding. (b)Test rig.

The closed-loop Hall current sensors are used for phase current detection. The response time of the current sensor is less than $1 \mu \mathrm{s}$. The brushless resolver is used for rotor position detection. The accuracy is within $10^{\prime}$.

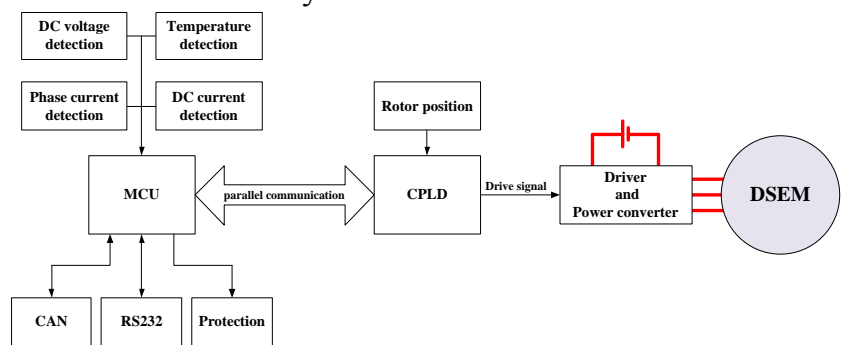

Fig. 22. Hardware platform diagram.

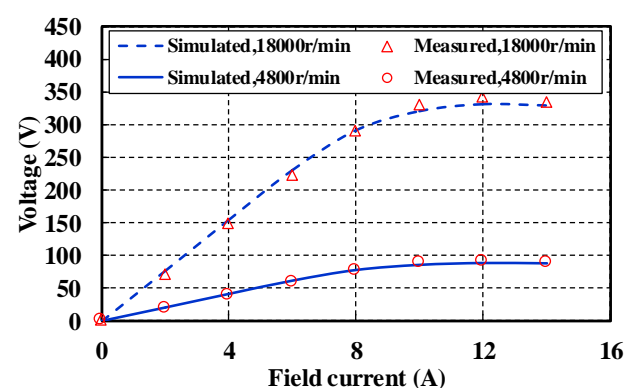

Fig. 23. Amplitude of line-to-line back-EMF versus field current without armature current.

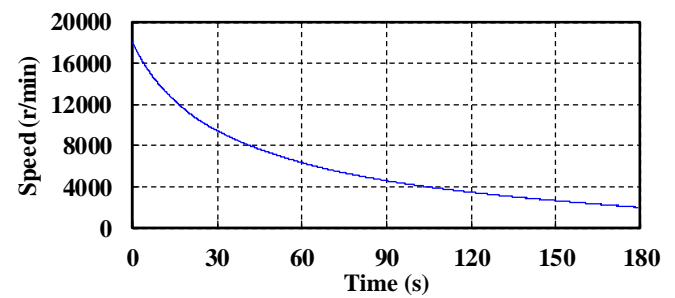

(a)

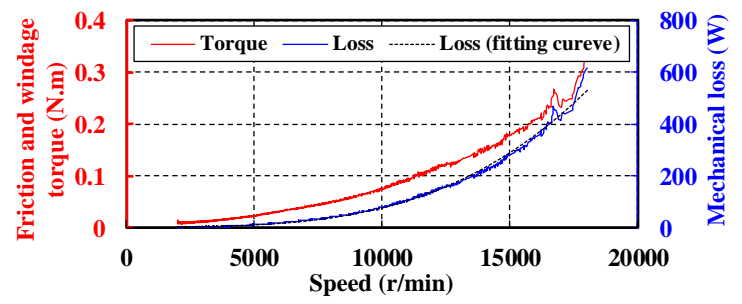

(b)

Fig. 24. Measurement of mechanical loss for high-speed operation. (a) Free-speed-down experiment. (b) Mechanical loss.

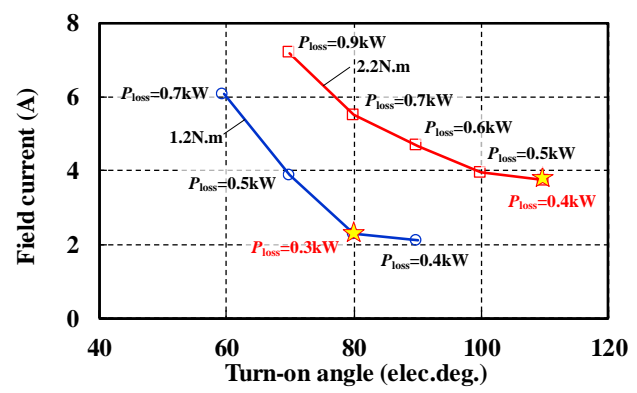

Fig. 25. Loss versus turn-on angle and field current for different torque requirements at $12000 \mathrm{r} / \mathrm{min}$.

The amplitude of line-to-line back-EMF is increased with the increase of the field current as shown in Fig. 23. The flux-path is susceptible to saturation when the field current is increased. Thus the amplitude of line-to-line back-EMF is increased slowly with the large field current. At $18000 \mathrm{r} / \mathrm{min}$, the backEMF is much higher than the DC-link voltage. In an event of 
the converter failure, the field current is cut off, and the backEMF is reduced to zero for safety.

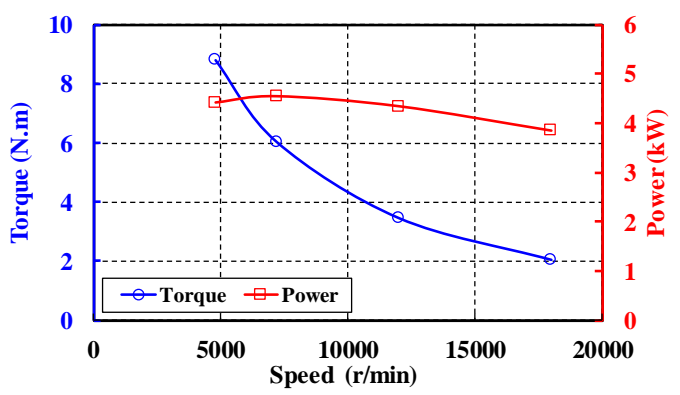

Fig. 26. Measurement of torque-speed curve. $\left(I_{\mathrm{f}}=7 \mathrm{~A}\right)$

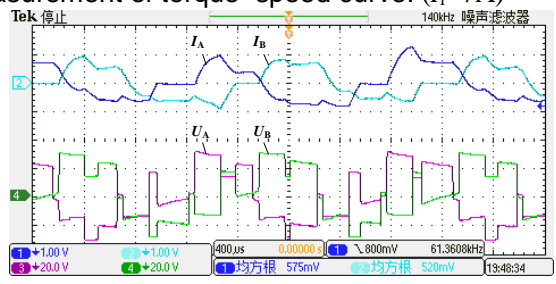

(a)

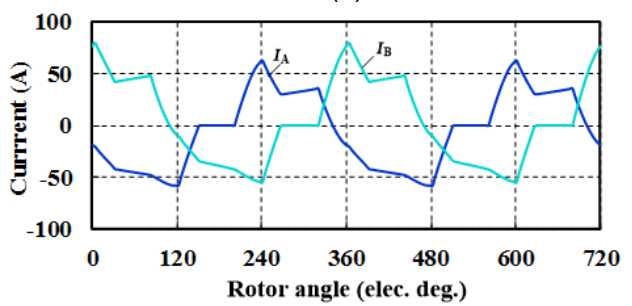

(b)

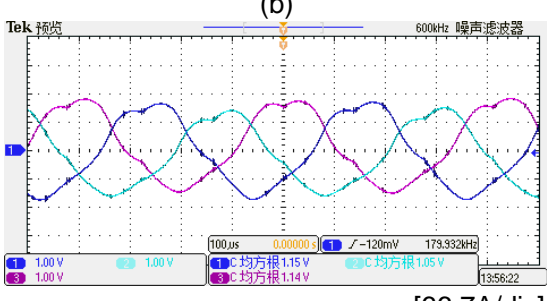

$[66.7 \mathrm{~A} / \mathrm{div}]$

(c)

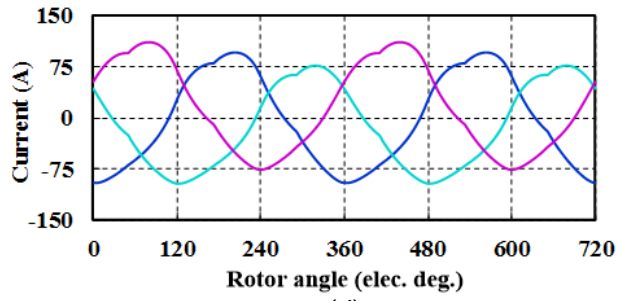

(d)

Fig. 27. Phase current and voltage waveforms. (a) Measured waveforms and (b) simulated waveforms $\left(\theta_{0 n}=40^{\circ}, l_{i}=4 \mathrm{~A}, n=4800 \mathrm{r} / \mathrm{min}\right)$. (c) Measured current waveforms and (d) simulated current waveforms $\left(\theta_{0 \mathrm{on}}=70^{\circ}, l_{\mathrm{f}}=6 \mathrm{~A}, n=18000 \mathrm{r} / \mathrm{min}\right)$.

The mechanical loss is measured by the free-speed-down experiment as shown in Fig. 24. The DSEM operates at $18000 \mathrm{r} / \mathrm{min}$ at no load, and then both the power converter and the field current regulator are cut off simultaneously. The DSEM decelerates from 18000r/min due to the bearing friction and windage as shown in Fig. 24(a). The drag torque is expressed as

$$
T_{d r a g}=-J \frac{d \omega}{d t}
$$

where $J$ is the moment of inertia of the rotor, $\omega$ is the mechanical angular velocity. Therefore the mechanical loss is obtained as shown in Fig. 24(b). The mechanical loss is basically in cubic relationship with the rotor speed. Because of the salient rotor structure and shaft-driven fan, the mechanical loss is high at high speed. The calculated loss for various torque requirement is shown in Fig. 25. The minimized loss is achieved at the points marked by pentagram.

Fig. 26 shows the measured torque-speed curve when the field current is set to 7A and the turn-on angle is regulated as shown in Fig. 19(b). The amplitude of line-to-line induced back-EMF is up to $260 \mathrm{~V}$ at $18000 \mathrm{r} / \mathrm{min}$ with field current of $7 \mathrm{~A}$, while the DC-link voltage is only $48 \mathrm{~V}$. The wide speed range is realized under lower DC-link voltage. The commutation accuracy at high speed and measurement deviation cause the difference between simulated and experimental results. The windage loss results in decrease of the output power at high speed. The phase current waveforms are shown in Fig. 27. Both the experimental and simulated waveforms are in good agreement.

\section{CONCLUSION}

In this paper, a dual-pulse mode control of a high-speed DSEM for the improvement of efficiency and torque capability under a low DC-link voltage is proposed. The influence of the excitation angles on the torque performance is investigated. The relatively lower loss is achieved when the turn-on angle is equal to reversal angle. The proper turn-on angle can reduce the backEMF, through the transformer EMF and flux-weakening armature reaction, and boost the phase current. The field current is regulated together with turn-on angle meeting the torque requirement for loss reduction. The dual-pulse mode control of the DSEM under high-speed operation is implemented over a wide speed range from $4800 \mathrm{r} / \mathrm{min}$ up to $18000 \mathrm{r} / \mathrm{min}$. The high efficiency is realized under the low DC-link voltage. The proposed control method contributes to better operation performance of the high-speed operated DSEM, and can be further applied for multi-phase DSEMs.

\section{REFERENCES}

[1] L. Yu, Z. Zhang, Z. Chen and Y. Yan, "Analysis and Verification of the Doubly Salient Brushless DC Generator for Automobile Auxiliary Power Unit Application," IEEE Transactions on Industrial Electronics, vol. 61, no. 12, pp. 6655-6663, Dec. 2014.

[2] Z. Chen, H. Wang and Y. Yan, "A Doubly Salient Starter/Generator With Two-Section Twisted-Rotor Structure for Potential Future Aerospace Application," IEEE Transactions on Industrial Electronics, vol. 59, no. 9, pp. 3588-3595, Sept. 2012.

[3] G. Zhao, W. Hua and J. Qi, "Comparative Study of Wound-Field FluxSwitching Machines and Switched Reluctance Machines," IEEE Transactions on Industry Applications, vol. 55, no. 3, pp. 2581-2591, May-June 2019.

[4] T. J. E. Miller, "Converter Volt-Ampere Requirements of the Switched Reluctance Motor Drive," IEEE Transactions on Industry Applications, vol. IA-21, no. 5, pp. 1136-1144, Sept. 1985.

[5] Y. Wang, Z. Zhang, R. Liang, W. Yuan and Y. Yan, "Torque Density Improvement of Doubly Salient Electromagnetic Machine With Asymmetric Current Control," IEEE Transactions on Industrial Electronics, vol. 63, no. 12, pp. 7434-7443, Dec. 2016.

[6] W. Jia and L. Xiao, "Research on control strategies for doubly salient electromagnetic machine," IET Electric Power Applications, vol. 11, no. 
8, pp. 1449-1456, May 2017

[7] I. Boldea, L. N. Tutelea, L. Parsa and D. Dorrell, "Automotive Electric Propulsion Systems With Reduced or No Permanent Magnets: An Overview," IEEE Transactions on Industrial Electronics, vol. 61, no. 10, pp. 5696-5711, Oct. 2014.

[8] J. Borg Bartolo, M. Degano, J. Espina and C. Gerada, "Design and Initial Testing of a High-Speed 45-kW Switched Reluctance Drive for Aerospace Application," IEEE Transactions on Industrial Electronics, vol. 64, no. 2, pp. 988-997, Feb. 2017.

[9] V. Madonna, P. Giangrande and M. Galea, "Electrical Power Generation in Aircraft: Review, Challenges, and Opportunities," IEEE Transactions on Transportation Electrification, vol. 4, no. 3, pp. 646-659, Sept. 2018.

[10] Y. Fan and K. T. Chau, "Design, Modeling, and Analysis of a Brushless Doubly Fed Doubly Salient Machine for Electric Vehicles," IEEE Transactions on Industry Applications, vol. 44, no. 3, pp. 727-734, MayJune 2008.

[11] V. P. Vujičić, "Minimization of Torque Ripple and Copper Losses in Switched Reluctance Drive," IEEE Transactions on Power Electronics, vol. 27, no. 1, pp. 388-399, Jan. 2012.

[12] F. Peng, J. Ye and A. Emadi, "A Digital PWM Current Controller for Switched Reluctance Motor Drives," IEEE Transactions on Power Electronics, vol. 31, no. 10, pp. 7087-7098, Oct. 2016.

[13] I. Kioskeridis and C. Mademlis, "Maximum efficiency in single-pulse controlled switched reluctance motor drives," IEEE Transactions on Energy Conversion, vol. 20, no. 4, pp. 809-817, Dec. 2005.

[14] N. Schofield, S. A. Long, D. Howe and M. McClelland, "Design of a Switched Reluctance Machine for Extended Speed Operation," IEEE Transactions on Industry Applications, vol. 45, no. 1, pp. 116-122, Jan.Feb. 2009.

[15] L. Schwager, A. Tüysüz, C. Zwyssig and J. W. Kolar, "Modeling and Comparison of Machine and Converter Losses for PWM and PAM in High-Speed Drives," IEEE Transactions on Industry Applications, vol. 50, no. 2, pp. 995-1006, March-April 2014.

[16] S. Xue et al., "Iron Loss Model for Electrical Machine Fed by Low Switching Frequency Inverter," IEEE Transactions on Magnetics, vol. 53, no. 11, pp. 1-4, Nov. 2017, Art no. 2801004.

[17] S. Iwasaki, R. P. Deodhar, Y. Liu, A. Pride, Z. Q. Zhu and J. J. Bremner, "Influence of PWM on the Proximity Loss in Permanent-Magnet Brushless AC Machines," IEEE Transactions on Industry Applications, vol. 45, no. 4, pp. 1359-1367, July-Aug. 2009.

[18] Z. Zhang, L. Yu, L. Sun, L. Qian and X. Huang, "Iron Loss Analysis of Doubly Salient Brushless DC Generators," IEEE Transactions on Industrial Electronics, vol. 62, no. 4, pp. 2156-2163, April 2015.

[19] S. Xue et al., "Iron Loss Model Under DC Bias Flux Density Considering Temperature Influence, " IEEE Transactions on Magnetics, vol. 53, no. 11, pp. 1-4, Nov. 2017, Art no. 6100804.

[20] C. R. Sullivan, "Optimal choice for number of strands in a litz-wire transformer winding," IEEE Transactions on Power Electronics, vol. 14, no. 2, pp. 283-291, Mar. 1999.

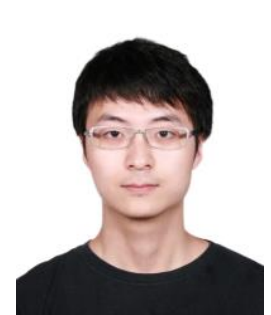

Li Yu (S'15-M'19) received the B.S. degree in electrical engineering from Nanjing University of Technology, Nanjing, China, in 2011, and received the M.S. and Ph.D. degrees in electrical engineering from Nanjing University of Aeronautics and Astronautics (NUAA), Nanjing, China, in 2014 and 2019, respectively. From March 2018 to March 2019, he was a visiting Ph.D. student with the Power Electronics, Machine, and Control Group (PEMC) at The University of Nottingham, Nottingham, U.K.

Since 2019, he has been a lecturer at Department of Electrical Engineering, NUAA. His main research interests include the doubly salient electric machine design and control for aircraft power system. He is the recipient of Best Paper Award in IEEE VPPC'2013.

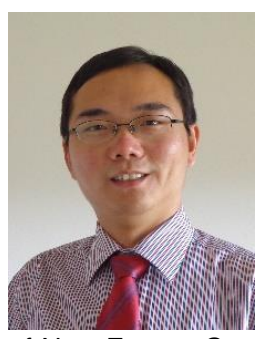

Zhuoran Zhang (M'09-SM'12) received the B.S. degree in measurement engineering and the M.S. and Ph.D. degrees in electrical engineering from Nanjing University of Aeronautics and Astronautics (NUAA), Nanjing, China, in 2000, 2003 and 2009, respectively.

Since 2003, he has been a member of the faculty at Department of Electrical Engineering, NUAA, where he is currently a full professor and vice director of Jiangsu Provincial Key Laboratory of New Energy Generation and Power Conversion. From Feb. 2012 to Jun. 2013, he was a visiting professor in Wisconsin Electric Machines and Power Electronics Consortium (WEMPEC), University of Wisconsin-Madison, U.S. From 2016 to 2017, he worked in Commercial Aircraft Corporation of China, Ltd. (COMAC) and was appointed as deputy director of electrical system designers of C919 civil jet aircraft.

His research interests include design and control of permanent magnet machines, hybrid excitation electric machines, and doubly salient electric machines for aircraft power, electric vehicles and renewable energy generation. He has authored or coauthored over 140 technical papers and two books, and is the holder of 36 issued patents in these areas.

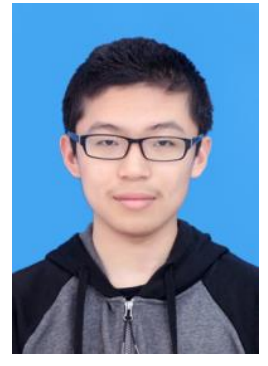

Zhangming Bian received the B.S. degree in electrical engineering from Nanjing University of Aeronautics and Astronautics (NUAA), Nanjing, China, in 2017. He is currently working toward the M.S. degree in electrical engineering at NUAA.

His main research interests include control of the doubly salient electric machine.

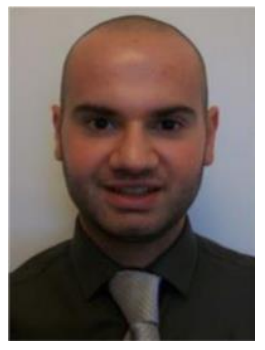

David Gerada received the Ph.D. degree in highspeed electrical machines from University of Nottingham, Nottingham, U.K., in 2012.

From 2007 to 2016, he was with the R\&D Department at Cummins, Stamford, U.K., first as an Electromagnetic Design Engineer (2007-2012), and then as a Senior Electromagnetic Design Engineer and Innovation Leader (2012-2016). At Cummins, he pioneered the design and development of high-speed electrical machines, transforming a challenging technology into a reliable one suitable for the transportation market, while establishing industry-wide-used metrics for such machinery. In 2016, he joined the University of Nottingham as a Senior Fellow in electrical machines, responsible for developing state-of-the-art electrical machines for future transportation which push existing technology boundaries, while propelling the new technologies to higher technology readiness levels.

Dr. Gerada is a Chartered Engineer in the U.K. and a member of the Institution of Engineering and Technology.

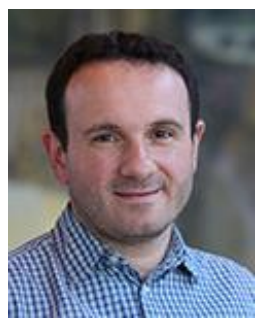

Chris Gerada (M'05-SM'12) received the Ph.D. degree in numerical modelling of electrical machines from The University of Nottingham, Nottingham, U.K., in 2005.

He subsequently worked as a Researcher with The University of Nottingham on highperformance electrical drives and on the design and modelling of electromagnetic actuators for aerospace applications. In 2008, he was appointed as a Lecturer in electrical machines; in 2011, as an Associate Professor; and in 2013, as a Professor at The University of Nottingham. He was awarded a Research Chair from the Royal Academy of Engineering in 2013 and his main research interests include the design and modelling of high-performance electric drives and machines.

Prof. Gerada serves as an Associate Editor for the IEEE TRANSACTIONS ON INDUSTRY APPLICATIONS and is the past Chair of the IEEE IES Electrical Machines Committee. 